\title{
Urinary neutrophil gelatinase-associated lipocalin identifies critically ill young children with acute kidney injury following intensive care admission: a prospective cohort study
}

\author{
Alexandra JM Zwiers ${ }^{1,2^{*}}$, Saskia N de Wildt ${ }^{1,2}$, Joost van Rosmalen ${ }^{3}$, Yolanda B de Rijke ${ }^{4,5}$, Erik AB Buijs ${ }^{1,2}$,
}

Dick Tibboel ${ }^{1,2}$ and Karlien Cransberg ${ }^{2}$

\begin{abstract}
Introduction: Children admitted to a pediatric intensive care unit (ICU) are at high risk of developing acute kidney injury (AKI). Although serum creatinine (SCr) levels are used in clinical practice, they are insensitive for early diagnosis of AKI. Urinary neutrophil gelatinase-associated lipocalin (UNGAL) and kidney injury molecule-1 (KIM-1) are novel AKI biomarkers whose performance in pediatric ICU patients is largely unknown. In this study, we aimed to characterize UNGAL and KIM-1 patterns in children following ICU admission and to assess their properties in relation to identifying children at risk for AKI development.
\end{abstract}

Methods: From June 2010 until January 2014, we conducted a prospective observational cohort study of term-born children ages 1 day to 1 year on mechanical ventilation. Blood and urine samples were obtained every 6 to 12 hours up to 72 hours post-admission. Blood samples were assayed for SCr, and urine samples were assayed for UNGAL and KIM-1. The RIFLE (risk, injury, failure, loss, end-stage renal disease) classification as 150\%, 200\% or 300\% of median SCr reference values was used to define AKI.

Results: A total of 100 children were included (80 survived). Their median age at admission was 27.7 days (interquartile range (IQR), 1.5 to 85.5). The median duration of mechanical ventilation was 5.8 days (IQR, 3.1 to 11.4). Thirty-five patients had evidence of AKI within the first 48 hours post-admission, of whom 24 (69\%) already had AKI when they entered the ICU. UNGAL and KIM-1 concentrations in AKI peaked between 6 to 12 hours and between 12 to 24 hours post-admission, respectively. The maximal area under the receiver operating characteristic curve (AUC) for UNGAL was 0.815 (95\% confidence interval $(\mathrm{Cl}), 0.685$ to $0.945, P<0.001)$ at 0 to 6 hours post-admission. The discriminative ability of KIM-1 was moderate, with a largest AUC of $0.737(95 \% \mathrm{Cl}, 0.628$ to $0.847 ; P<0.001)$ at 12 to 24 hours post-admission. At the optimal cutoff point $(126 \mathrm{ng} / \mathrm{ml})$, uNGAL concentration predicted AKI development correctly in 16 (84\%) of 19 children, up to 24 hours before a rise in SCr became apparent.

Conclusions: Levels of UNGAL and KIM-1 increase in patients with AKI following ICU admission and peak at 6 to 12 hours and 12 to 24 hours post-admission, respectively. UNGAL seems to be a reliable marker for identifying children who will develop AKI 24 hours later.

\footnotetext{
* Correspondence: a.zwiers@erasmusmc.nl

${ }^{1}$ Intensive Care and Department of Pediatric Surgery, Wytemaweg 80, 3015

CN Rotterdam, the Netherlands

${ }^{2}$ Department of Pediatric Nephrology, Erasmus Medical Center-Sophia

Children's Hospital, Wytemaweg 80, 3015 CN Rotterdam, the Netherlands

Full list of author information is available at the end of the article
}

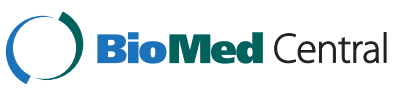

(c) 2015 Zwiers et al.; licensee BioMed Central. This is an Open Access article distributed under the terms of the Creative Commons Attribution License (http://creativecommons.org/licenses/by/4.0), which permits unrestricted use, distribution, and reproduction in any medium, provided the original work is properly credited. The Creative Commons Public Domain Dedication waiver (http://creativecommons.org/publicdomain/zero/1.0/) applies to the data made available in this article, unless otherwise stated. 


\section{Introduction}

Acute kidney injury (AKI) is a frequent and serious complication in critically ill children [1-7]. Moreover, it has been shown to be an independent risk factor for mortality, prolonged length of intensive care unit (ICU) stay and prolonged mechanical ventilation $[1,2,5]$. Current consensus criteria for diagnosing AKI are based on changes in serum creatinine ( $\mathrm{SCr}$ ) and urine output $[4,8]$. One must realize, however, that $\mathrm{SCr}$ is an indicator of glomerular function rather than renal tubular cell damage, which typically occurs during the initial phase of AKI in ICU patients $[9,10]$. In addition, a substantial number of functioning nephrons have to be compromised before changes in SCr levels become evident [11]. Moreover, $\mathrm{SCr}$ is influenced by factors unrelated to renal function and in the newborn reflects maternal levels immediately after birth [11,12]. Altogether, $\mathrm{SCr}$ is increasingly considered a late and not very sensitive marker for diagnosing AKI.

Therefore, research has increasingly focused on the identification of novel, more sensitive biomarkers for renal injury, especially tubular, injury, including urinary neutrophil gelatinase-associated lipocalin (uNGAL) and kidney injury molecule-1 (KIM-1) [13]. NGAL is a small, $25 \mathrm{kDa}$ protein initially discovered in activated human neutrophils [14]. NGAL is expressed in limited quantities in other human tissues, including the lungs, spleen and kidneys, where it is thought to inhibit bacterial growth, scavenge iron and induce epithelial growth [14-18]. Plasma NGAL is freely filtered by the glomerulus and then largely reabsorbed by proximal tubular cells [19]. Upon renal tubular injury, NGAL reabsorption may be decreased, whereas NGAL de novo synthesis in epithelial cells of the loop of Henle and of distal tubule segments is strongly upregulated, after which it is found in high concentrations in the urine [20]. KIM-1 is a $104 \mathrm{kDa}$ type I transmembrane glycoprotein that contains both an immunoglobulin-like domain and a mucin domain in its extracellular portion [21]. It is expressed in low levels in healthy proximal tubule cells and is thought to promote apoptotic and necrotic cell clearance [22]. Upon kidney ischemia or toxicity, KIM-1 is highly upregulated and shed into the extracellular space and urine [21,22].

The usefulness of uNGAL was first recognized by Mishra and colleagues, who demonstrated that postoperative UNGAL levels in children at 2 hours after cardiopulmonary bypass (CPB) had a nearly $100 \%$ accuracy for predicting AKI at 24 to 72 hours [23]. Subsequent studies, mainly in adults, in clinical settings such as critical care and kidney transplantation confirmed this finding $[24,25]$. KIM-1, on the other hand, has been systematically investigated only in patients undergoing $\mathrm{CPB}$ and in a small sample of asphyxiated neonates $[26,27]$.
Zappitelli and colleagues [28] were the first to evaluate UNGAL in a large, heterogeneous group of pediatric ICU (PICU) patients. They found a good diagnostic marker for development of AKI and persistent AKI for $\geq 48$ hours, but not for AKI if uNGAL had been measured after a rise in SCr [28]. In later studies focused on cutoff points for AKI prediction specifically in PICU patients, researchers evaluated biomarker combinations and even suggested uNGAL as a predictor of mortality $[29,30]$.

None of these previous studies, however, provided insight into biomarker evolution using time intervals based on the hours shortly after ICU admission. Besides, for these studies, authors reported data for subjects with age ranges widely varying from 1 week to 21 years [27-31]. None focused on children up to 1 year of age, even though this age group is particularly vulnerable to renal injury during the physiological evolution of renal function. Therefore, our aim in the present study was to characterize temporary uNGAL and KIM-1 patterns in the 3 days following ICU admission in a large cohort of critically ill children up to 1 year of age. Secondarily, we aimed to assess whether the levels of these biomarkers during the first 24 hours of PICU admission can reliably identify children at risk for AKI development within 48 hours following admission.

\section{Material and methods}

\section{Setting}

From June 2010 until January 2014, a single-center prospective observational cohort study was conducted in the level III ICU of the Erasmus Medical Center-Sophia Children's Hospital, Rotterdam, the Netherlands. Considered for enrollment were children (born later than 37 weeks of gestational age) between the ages of 1 day and 1 year admitted to the ICU and requiring endotracheal intubation and mechanical ventilation. Patients were not eligible for inclusion if (1) they had congenital abnormalities of the kidney or urinary tract, (2) death was anticipated within 24 hours or (3) they received mechanical ventilation for other reasons (for example, neuromuscular disease). Patients were excluded when treatment with extracorporeal membrane oxygenation was required within the study period. The study protocol was approved by the local medical ethics review board of the Erasmus Medical Center. A deferred consent process was used whereby written informed consent was obtained from the primary caregivers within 12 hours following the study start. The collected blood and urine specimens of those children for whom consent was withdrawn were destroyed ( $\mathrm{n}=10$ children, maximum of $1.4 \mathrm{ml}$ of blood per patient).

\section{Sample collection and analytical procedures}

Upon ICU admission, blood and urine samples were prospectively collected concurrently during the patient's 
admission between 0 and 6 hours (T0), 6 and 12 hours (T1), 12 and 24 hours (T2), 24 and 36 hours (T3), 36 and 48 hours (T4) and 48 and 72 hours (T5). For each time frame, $0.7 \mathrm{ml}$ of blood was drawn with an indwelling arterial line, if available, or by capillary or venous puncture. Urine samples were collected using a bladder catheter. To collect $3 \mathrm{ml}$ of freshly voided urine, the urine collection bag was emptied 1 hour prior to each sampling time frame. Urine samples were left refrigerated for sedimentation for 2 to 3 hours, aliquoted and stored within 4 hours after collection at $-80^{\circ} \mathrm{C}$ until performing the assay.

Creatinine concentrations were measured in the hospital's clinical chemical laboratory by using an enzymatic assay (Creatinine Plus; Roche Diagnostics, Branchburg, NJ, USA) on a cobas 8000 analyzer (Roche Diagnostics). During the period of sample collection, the interassay coefficient of variation (CV) was less than $2.6 \%$.

uNGAL was measured using the latest UNGAL chemiluminescence microparticle immunoassay developed for a standardized clinical platform (ARCHITECT immunoassay analyzer; Abbott Diagnostics Division, Abbott Laboratories, Abbott Park, IL, USA). The mean interassay CV for UNGAL was $5.3 \%$ at a concentration of $19.4 \mathrm{ng} / \mathrm{ml}$. The limit of quantification (LoQ) of uNGAL was $3.0 \mathrm{ng} / \mathrm{ml}$, and the upper limit of quantitation was $6,000 \mathrm{ng} / \mathrm{ml}$. The reagents and calibrator for the uNGAL assays were kindly supplied by Abbott Diagnostics. KIM-1 was measured using a commercially available enzyme-linked immunosorbent assay kit (BioAssay Works, Ijamsville, MD, USA). The mean interassay CV for KIM-1 was $<14 \%$ at a concentration of $0.17 \mathrm{ng} / \mathrm{ml}$. The LoQ of KIM-1 was $0.08 \mathrm{ng} / \mathrm{ml}$. uNGAL and KIM-1 levels are expressed in absolute values (nanograms per milliliter).

\section{Data collection}

Recorded patient data included clinical characteristics and results of laboratory tests. More specifically, sex, gestational age and birth weight, as well as age, body weight and diagnosis at admission, were collected. The Pediatric Risk of Mortality II (PRISM II) score and Pediatric Index of Mortality 2 score were collected as an indication of severity of illness [32,33]. Furthermore, cardiac arrest upon ICU admission and type of mechanical ventilation were registered, together with the fraction of inspired oxygen at the time of intubation, the need for nitric oxide ventilation, and the administration of vasopressor drugs, diuretics (furosemide or bumetanide) or aminoglycosides (gentamicin, tobramycin or amikacin). Last, data on the following outcomes were collected: treatment with renal replacement therapy, duration of mechanical ventilation, lengths of ICU and hospital stay and survival until ICU discharge.

\section{Definitions}

AKI was defined according to the maximal SCr-based RIFLE (risk (R), injury (I), failure (F), loss, end-stage renal disease) score obtained within the first 48 hours following admission. The RIFLE classifications we used defined three grades of increasing AKI severity, including R (risk for kidney injury), I (injury to the kidney) and F (failure of kidney function) [8]. RIFLE outcome categories L (loss of renal function) and $\mathrm{E}$ (end-stage renal disease) were not applicable, as the study was restricted to the first 7 days following ICU admission. Because all children enrolled were younger than 1 year of age, most did not have data available for baseline $\mathrm{SCr}$ concentrations pre-ICU admission, nor is there an algorithm available to calculate estimated glomerular filtration rate, which is why the RIFLE categories risk, injury and failure were defined as $\mathrm{SCr}$ concentrations above $150 \%$, $200 \%$ and $300 \%$, respectively, of the median age-specific $\mathrm{SCr}$ reference value. These $\mathrm{SCr}$ reference values were obtained from a large cohort of children without kidney disease by using short age intervals ranging from 1 day in the first week after birth up to 3 months at the end of the first year of age [34]. Persistent AKI was defined as lack of improvement of RIFLE score within 72 hours post-admission.

\section{Statistical analysis}

Unless indicated otherwise, continuous data are expressed as median values with interquartile ranges (IQRs) and discrete data as numbers with percentages. Patients were grouped according to whether they lacked AKI or had AKI (based on RIFLE score for risk, injury and/or failure) within 48 hours following admission. Clinical characteristics and biomarker levels were compared between AKI and non-AKI patients using univariate analyses for continuous variables (Mann-Whitney $U$ test) and categorical variables (Pearson's $\chi^{2}$ test or Fisher's exact test, as appropriate). Biomarker levels were also compared between RIFLE strata and diagnostic categories using univariate overall comparisons between groups (Kruskal-Wallis test). Receiver operating characteristic (ROC) curves were generated for the occurrence of AKI within 48 hours following intubation using biomarker levels within three different time frames (T0, T1 and T2: 0 to 6 hours, 6 to 12 hours and 12 to 24 hours, respectively) as well as 24-hour peak levels. The areas under the ROC curve (AUCs) with 95\% confidence intervals $(95 \% \mathrm{CI})$ were calculated. Also, for each time frame, the optimal cutoff value based on the Youden index was calculated with corresponding sensitivity and specificity. Using those cutoff values, sensitivity and specificity of both biomarkers for predicting AKI, as well as the positive and negative predictive values, were calculated for patients who developed AKI later within the 
study period ( $<72$ hours post-admission) after being considered AKI-free upon admission. Of these patients, the timing and absolute values of maximum biomarker levels in urine samples preceding AKI were compared with biomarker levels in the first urine samples of controls (critically ill children who did not have AKI). A two-sided $P$-value of 0.05 was considered the limit of significance in all analyses. Data were analyzed using IBM SPSS Statistics version 21 software (IBM, Armonk, NY, USA).

\section{Results}

\section{Patients}

A total of 110 patients were initially included by deferred consent. However, because consent was withdrawn by $10(9 \%)$ parents, 100 patients were ultimately enrolled in the study. Table 1 details the characteristics of all patients stratified by occurrence of AKI within 48 hours post-admission. At admission, median age was 27.7 days (IQR, 1.5 to 85.5), and median body weight was $3.8 \mathrm{~kg}$ (IQR, 3.2 to 5.3 ). The most common primary diagnoses were congenital diaphragmatic hernia $(\mathrm{n}=23(23 \%))$ and respiratory failure $(n=20(20 \%))$. For all patients, the median duration of mechanical ventilation was 5.8 days (IQR, 3.1 to 11.4), and the median ICU stay was 10.0 days (IQR, 6.1 to 27.0). Seventeen patients (17\%) died during admission after a median ICU stay of 11.7 days (IQR, 4.4 to 27.2).

\section{Acute kidney injury}

Thirty-five patients (35\%) met the criteria for AKI within 48 hours following ICU admission. Fifteen (42\%) of those were classified as RIFLE-R, 10 (29\%) as RIFLE-I and $10(29 \%)$ as RIFLE-F. One patient classified as RIFLE-F received renal replacement therapy starting 2 days post-admission. Twenty-four (69\%) of the thirtyfive patients with AKI already met the criteria for AKI at the time of admission (risk: $\mathrm{n}=6$ (25\%); injury: $\mathrm{n}=8$ (33\%); failure: $\mathrm{n}=10(42 \%)$ ).

Age, weight, diagnosis and cardiac arrest experienced upon ICU admission did not significantly differ between patients who developed AKI within 48 hours following admission and those who did not (Table 1). Nonetheless, patients in the former group were more severely ill on admission, as reflected by a significantly higher PRISM II score (48.9 (IQR, 25.5 to 77.1)) than that assigned to non-AKI patients (25.1 (IQR, 10.10 to 54.1$)(P<0.001$ by Mann-Whitney $U$ test). Moreover, patients with AKI were ventilated almost twice as long as non-AKI patients, although type of mechanical ventilation, fraction of inspired oxygen and need for nitric oxide ventilation did not differ. Patients with AKI more often received two or more types of vasopressor drugs at intubation and had longer ICU and hospital lengths of stay. In contrast, there was no difference in the prescription of diuretic drugs and aminoglycosides between AKI and non-AKI patients. Last, the overall mortality rate in patients with AKI was significantly higher than that of non-AKI patients (32\% versus $14 \% ; P=0.027$ by Pearson's $X^{2}$ test).

\section{Biomarker patterns post-admission}

In total, 491 urine samples were collected (that is, 86\% of all scheduled samples (5 samples (IQR, 4 to 5) per patient). Sampling was not feasible in cases of anuria, discontinuation of bladder catheterization or logistical problems. The median uNGAL concentration for all urine specimens was $39.5 \mathrm{ng} / \mathrm{ml}$ (IQR, 12.4 to $168.1 \mathrm{ng} / \mathrm{ml}$ ) and the median KIM-1 concentration was $0.14 \mathrm{ng} / \mathrm{ml}$ (IQR, 0.08 to $0.30 \mathrm{ng} / \mathrm{ml}$ ). For patients with AKI, the median UNGAL and KIM-1 concentrations were $107 \mathrm{ng} / \mathrm{ml}$ (IQR, 22.4 to 935) and $0.19 \mathrm{ng} / \mathrm{ml}$ (IQR, 0.10 to 0.43 ), respectively, which were significantly higher than those for non-AKI patients: uNGAL of $23.2 \mathrm{ng} / \mathrm{ml}$ (IQR, 9.6 to 93) and KIM-1 of $0.13 \mathrm{ng} / \mathrm{ml}$ (IQR, 0.08 to 0.25 ) (both $P$-values $<0.001$ by Mann-Whitney $U$ test).

Figure 1 presents the patterns of median uNGAL and KIM-1 levels from 0 to 72 hours following ICU admission. Both patterns showed an increase; the mean uNGAL concentration peaked at 6 to 12 hours, and the mean KIM-1 concentration peaked at 12 to 24 hours. UNGAL levels were significantly higher in the patients who developed AKI than in the non-AKI patients at all time frames except for T6 (48 to 72 hours) (all $P$-values $\leq 0.038$ by Mann-Whitney $U$ test). KIM-1 levels were significantly higher in patients with AKI only at T2 (12 to 24 hours) and T3 (24 to 36 hours) (both $P$-values $\leq 0.041$ by Mann-Whitney $U$ test). Table 2 shows the uNGAL and KIM-1 concentrations for T0 (0 to 6 hours), T1 (6 to 12 hours) and T2 (12 to 24 hours) and the peak levels within 24 hours by $\mathrm{SCr}$ based RIFLE strata. Worse RIFLE status was significantly associated with higher UNGAL and KIM-1 levels (all $P$-values $\leq 0.018$ by Kruskal-Wallis test). Compared across diagnostic categories, uNGAL and KIM-1 concentrations were both highest in patients with sepsis, especially those who met the AKI criteria (both $P$-values $<0.001$ by Kruskal-Wallis test) (Figure 2).

Urinary neutrophil gelatinase-associated lipocalin, kidney injury molecule- 1 and mortality

Seventeen patients died during admission. Three of these non-survivors died within the first 72 hours, of whom one was classified in the non-AKI group (died after 66 hours, peak uNGAL value of $114 \mathrm{ng} / \mathrm{ml}$ ) and two were in the AKI-group (died after 46 and 54 hours, respectively, both with peak uNGAL values 
Table 1 Patient characteristics grouped according to occurrence of acute kidney injury ${ }^{a}$

\begin{tabular}{|c|c|c|c|c|}
\hline & All patients $(n=100)$ & Non-AKI $(n=65)$ & AKI $(n=35)$ & $P$-value ${ }^{\mathrm{b}}$ \\
\hline \multicolumn{5}{|l|}{ Baseline characteristics } \\
\hline Male sex & $66(66)$ & $42(65)$ & $24(69)$ & $0.690^{c}$ \\
\hline Gestational age, wk & $39.0(37.6$ to 40.0$)$ & 38.9 (37.8 to 40.0$)$ & 39.0 (37.4 to 40.0$)$ & $0.861^{d}$ \\
\hline Birth weight, kg & 3.1 (2.8 to 3.6$)$ & 3.1 (2.8 to 3.5$)$ & 3.1 (2.8 to 3.6$)$ & $0.989^{d}$ \\
\hline \multicolumn{5}{|l|}{ Clinical characteristics at intubation } \\
\hline Age, days & $27.7(1.5$ to 85.5$)$ & $27.1(1.8$ to 71.4$)$ & 30.3 (1.4 to 115.0$)$ & $0.667^{d}$ \\
\hline Weight, kg & 3.8 (3.2 to 5.2$)$ & 3.7 (3.3 to 5.0$)$ & $3.8(3.1-6.0)$ & $0.745^{\mathrm{d}}$ \\
\hline \multicolumn{5}{|l|}{ Admission diagnosis } \\
\hline Congenital diaphragmatic hernia & $23(23)$ & $16(25)$ & $7(20)$ & $0.132^{c}$ \\
\hline Respiratory failure & $20(20)$ & $11(17)$ & $9(26)$ & \\
\hline Cardiac failure & $18(18)$ & $8(12)$ & $10(28)$ & \\
\hline RSV bronchiolitis & $17(17)$ & $14(21)$ & $3(9)$ & \\
\hline Sepsis & $14(14)$ & $9(14)$ & $5(14)$ & \\
\hline Other & $8(8)$ & $7(11)$ & $1(3)$ & \\
\hline Cardiac arrest on ICU admission, yes & $10(10)$ & $5(8)$ & $5(14)$ & $0.283^{c}$ \\
\hline \multicolumn{5}{|l|}{ Severity of illness at ICU admission } \\
\hline PIM2, \% & 9.8 (3.4 to 18.8$)$ & $7.0(1.7$ to 12.0$)$ & $15.9(8.4$ to 38.1$)$ & $0.011^{d}$ \\
\hline PRISM II, \% & $33.8(11.0$ to 64.5$)$ & 25.7 (10.1 to 54.1$)$ & 48.9 (25.5 to 77.1$)$ & $<0.001^{d}$ \\
\hline \multicolumn{5}{|l|}{ Type of mechanical ventilation } \\
\hline Pressure control & $68(68)$ & $45(69)$ & $23(66)$ & $0.671^{c}$ \\
\hline Pressure-regulated volume control & $19(19)$ & $11(17)$ & $8(23)$ & \\
\hline High-frequency ventilation & $11(11)$ & $7(11)$ & $4(11)$ & \\
\hline Pressure support & $2(2)$ & $2(3)$ & - & \\
\hline Fraction of inspired oxygen at intubation, percentage & 59 (40 to 94$)$ & 55 (40 to 90$)$ & 68 (39 to 100$)$ & $0.422^{d}$ \\
\hline Need for nitric oxide ventilation at intubation, yes & $18(18)$ & $10(15)$ & $8(23)$ & $0.354^{c}$ \\
\hline Need for two or more vasopressors at intubation, yes & $49(49)$ & $24(37)$ & $25(71)$ & $0.001^{c}$ \\
\hline Diuretic drugs, yes & $77(76)$ & $46(71)$ & $30(86)$ & $0.095^{d}$ \\
\hline Aminoglycosides, yes & $37(37)$ & $24(36)$ & $13(37)$ & $0.983^{\mathrm{d}}$ \\
\hline \multicolumn{5}{|l|}{ Outcomes } \\
\hline Need for renal replacement therapy, yes & $1(1)$ & - & $1(3)$ & $\mathrm{N} / \mathrm{A}$ \\
\hline Duration of mechanical ventilation, days & 5.8 (3.1 to 11.4$)$ & 4.4 (3.0 to 8.3$)$ & 8.3 (5.6 to 19.1$)$ & $0.001^{d}$ \\
\hline Length of ICU stay, days & $10.0(6.1$ to 27.0$)$ & $8.3(5.8$ to 15.9$)$ & 19.2 (7.8 to 35.6$)$ & $0.002^{d}$ \\
\hline Length of hospital stay, days & 15.9 (8.1 to 38.0$)$ & $11.6(6.5$ to 27.9$)$ & $27.0(11.1$ to 46.9$)$ & $0.015^{d}$ \\
\hline Mortality & $20(20)$ & $9(14)$ & $11(32)$ & $0.027^{c}$ \\
\hline ICU & 17 & 7 & 10 & $\mathrm{~N} / \mathrm{A}$ \\
\hline Time from admission until death, days & 11.7 (4.4 to 27.2$)$ & 9.9 (3.4 to 17.0$)$ & 18.7 (6.7 to 45.0$)$ & N/A \\
\hline
\end{tabular}

${ }^{a}$ AKI, Acute kidney injury; ICU, Intensive care unit; N/A, Not applicable; PIM2, Pediatric Index of Mortality 2; PRISM II, Pediatric Risk of Mortality II; RSV, Respiratory syncytial virus. Patient demographic data and clinical characteristics of all patients enrolled, grouped according to the development of AKI (yes or no), are shown. AKI was defined according to the highest RIFLE (risk, injury, failure, loss, end-stage renal disease) score attained within 48 hours following admission. The RIFLE categories risk, injury and failure were defined as, respectively, serum creatinine (SCr) above $150 \%, 200 \%$ and $300 \%$ of the median age-specific SCr reference values. Continuous data are expressed as median (interquartile range), and categorical data are expressed as number (\%). ${ }^{\mathrm{b}} \mathrm{P}$-values indicate comparison between $A K I$ and non-AKI patients using univariate analyses. 'Pearson's $x^{2}$ test or Fisher's exact test, as appropriate, for categorical variables. ${ }^{d}$ Mann-Whitney $U$ test for continuous variables.

of $6,000 \mathrm{ng} / \mathrm{ml}$ ). Non-survivors' uNGAL levels at 12 to 24 hours post-admission, as well as their 24-hour peak levels, were higher than those of survivors $(P$-values $\leq 0.009$ by Mann-Whitney $U$ test). There was no significant difference between survivors and non-survivors with regard to KIM-1 levels (all $P$-values $>0.05$ ). 

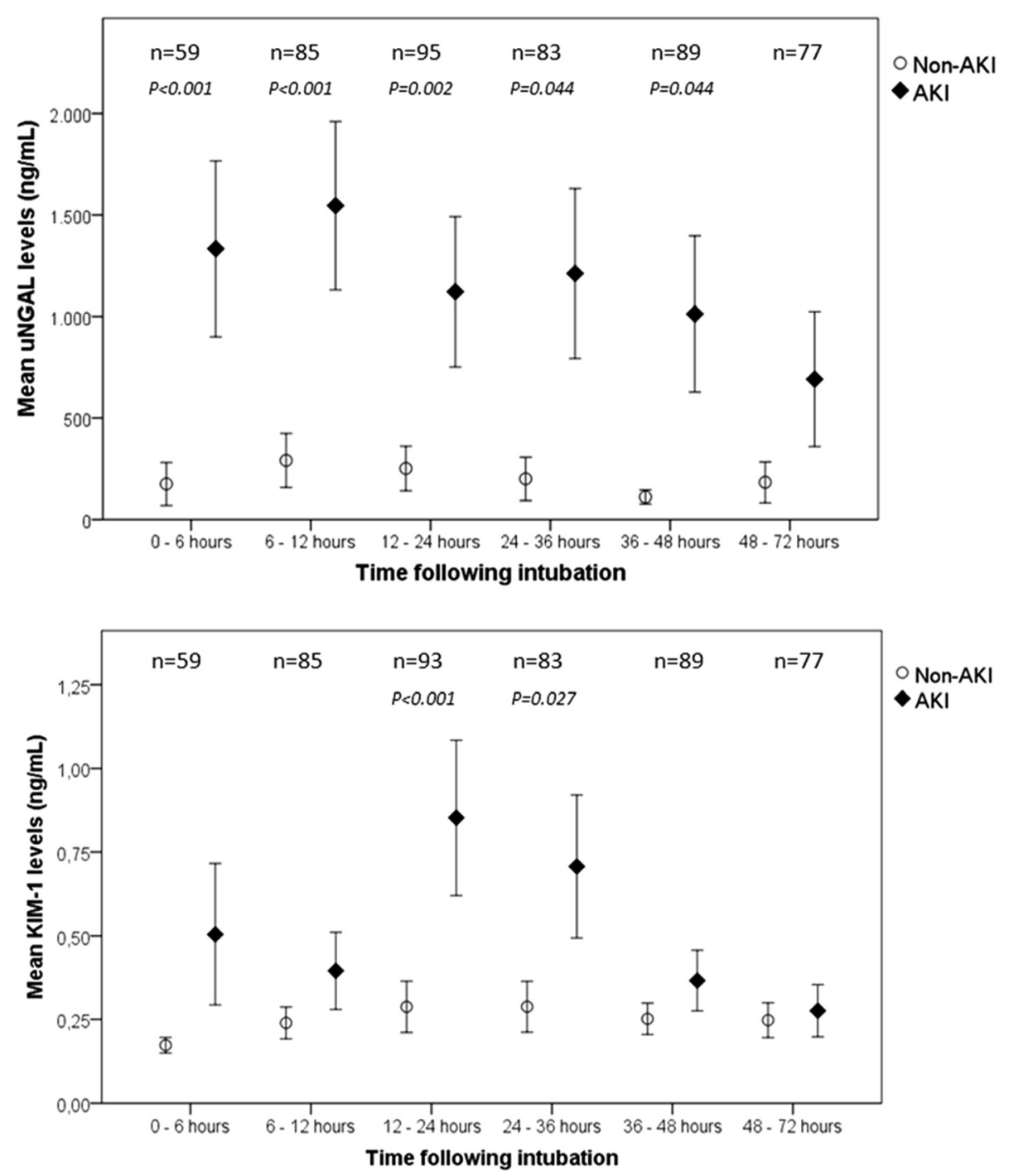

Figure 1 Clinical course of mean urinary neutrophil gelatinase-associated lipocalin and kidney injury molecule-1 levels from 0 to 72 hours following intubation, stratified by occurrence of acute kidney injury within 48 hours post-admission. Data represent the mean ( \pm 1 standard error of the mean). The filled diamonds represent patients with acute kidney injury (AKI), and the open circles represent non-AKI patients. Differences were assessed for each biomarker per time frame using Mann-Whitney $U$ tests. KIM-1, Kidney injury molecule-1; UNGAL, Urinary neutrophil gelatinase-associated lipocalin.

\section{Area under the receiver operating characteristic curve analysis}

Table 3 shows the AUCs for the prediction of the development of AKI within 48 hours following admission for both biomarkers at T0, T1 and T2, as well as for 24hour peak levels. The maximal AUC for UNGAL was 0.815 (95\% CI, 0.685 to $0.945 ; P$-value $<0.001)$ at T0 (0 to 6 hours), with an optimal cutoff value of $126 \mathrm{ng} / \mathrm{ml}$ with a sensitivity of $76 \%$ and a specificity of $84 \%$. The AUCs for UNGAL were 0.780 (95\% CI, 0.678 to $0.882 ; P$-value $<0.001)$ at T1, $0.711(95 \% \mathrm{CI}$, 0.599 to $0.824 ; P$-value $=0.001)$ at T2 and $0.811(95 \% \mathrm{CI}$, 0.719 to $0.902 ; P$-value $<0.001$ ) for the 24 -hour peak levels. KIM-1 was moderately discriminative only at T2, with an
AUC of 0.737 (95\% CI, 0.628 to 0.847 ; $P$-value $<0.001$ ) and an optimal cutoff value of $0.19 \mathrm{ng} / \mathrm{ml}$ with a sensitivity of $72 \%$ and specificity of $67 \%$. Figure 3 shows the ROC curve of UNGAL and KIM-1 levels at T0, T1 and T2 and for the 24-hour peak levels.

\section{Urinary neutrophil gelatinase-associated lipocalin and} kidney injury molecule-1 concentrations preceding acute kidney injury

Twenty-four patients already met the AKI criteria at the time of ICU admission, and nineteen other patients developed AKI later within the 72-hour admission (eleven within 48 hours and another eight between 48 and 72 hours post-admission). These 19 patients reached 
Table 2 T0, T1, T2 and peak urinary neutrophil gelatinase-associated lipocalin and kidney injury molecule-1 concentrations by serum creatinine-based RIFLE status within $\mathbf{4 8}$ hours following admission ${ }^{a}$

\begin{tabular}{|c|c|c|c|c|c|}
\hline Measurement, number of patients & Non-AKI, $n=65$ & RIFLE-Risk, $n=15$ & RIFLE-Injury, $\mathrm{n}=10$ & RIFLE-Failure, $n=10$ & $P$-value \\
\hline \multicolumn{6}{|l|}{ T0, 0 to $6 \mathrm{hr}$} \\
\hline uNGAL $(n g / m l), n=59$ & $31(16$ to 111$)$ & 396 (70to 1,250) & 385 (77 to 1,987$)$ & $1,873$ (484 to 3,936$)$ & $<0.001$ \\
\hline KIM-1 (ng/ml), n = 59 & 0.11 (0.08 to 0.19) & 0.18 (0.13 to 0.28$)$ & 0.10 (0.08 to 0.11$)$ & 1.2 (0.4 to 3.5$)$ & 0.004 \\
\hline \multicolumn{6}{|l|}{$\mathrm{T} 1,6$ to $12 \mathrm{hr}$} \\
\hline uNGAL $(n g / m l), n=85$ & 21 (8 to 116$)$ & 114 (61 to 420$)$ & 275 (11 to 4630$)$ & 2430 (727 to 6000) & $<0.001$ \\
\hline $\mathrm{KIM}-1(\mathrm{ng} / \mathrm{ml}), \mathrm{n}=85$ & 0.11 (0.08 to 0.27$)$ & 0.10 (0.08 to 0.29$)$ & 0.12 (0.08 to 0.16$)$ & 0.35 (0.29 to 1.21$)$ & 0.018 \\
\hline \multicolumn{6}{|l|}{$\mathrm{T} 2,12$ to $24 \mathrm{hr}$} \\
\hline uNGAL $(n g / m l), n=95$ & 22 (10 to 98$)$ & 34 (22 to 200) & 47 (26 to 1935$)$ & 979 (301 to 6000) & 0.001 \\
\hline $\mathrm{KIM}-1$ (ng/ml), n = 93 & 0.16 (0.08 to 0.28$)$ & $0.26(0.11$ to 0.56$)$ & $0.30(0.12$ to 0.41$)$ & 0.47 (0.26 to 2.15 ) & 0.002 \\
\hline \multicolumn{6}{|l|}{ 24-hr peak level } \\
\hline uNGAL (ng/ml), $n=100$ & 59 (16 to 136$)$ & 225 (89 to 730$)$ & 385 (56 to 3938$)$ & 1495 (387 to 6000) & $<0.001$ \\
\hline KIM-1 (ng/ml), $\mathrm{n}=100$ & 0.17 (0.08 to 0.34$)$ & 0.26 (0.11 to 0.56$)$ & 0.25 (0.10 to 0.41$)$ & 0.86 (0.44 to 2.15$)$ & 0.001 \\
\hline
\end{tabular}

${ }^{a}$ AKI, Acute kidney injury; KIM-1, Kidney injury molecule-1; RIFLE, Risk, injury, failure, loss, end-stage renal disease; SCr, Serum creatinine; uNGAL, Urinary neutrophil gelatinase-associated lipocalin. Data are expressed as median (interquartile range). $P$-values indicate overall comparison of all groups (that is, non-AKI versus Risk versus Injury versus Failure). Intergroup differences were assessed using the Kruskal-Wallis test. RIFLE categories risk, injury and failure were defined as, respectively, serum creatinine (SCr) above $150 \%, 200 \%$ and $300 \%$ of the median age-specific SCr reference values.

RIFLE-Risk level or higher at a median of 34 hours (IQR, 20 to 53) post-admission (Risk: $\mathrm{n}=16$ (84\%); Injury: $n=3(16 \%))$. For the analysis of biomarkers preceding AKI, the time point at which AKI first occurred was recoded to T0. All available uNGAL and KIM-1 measurements preceding this time point were recoded relative to T0 (Figure 4). Using the optimal cutoff value for uNGAL (126 ng/ml) and KIM-1 $(0.19 \mathrm{ng} / \mathrm{ml})$ levels as described above, uNGAL was the most sensitive biomarker for predicting the development of AKI (that is, in 16 (84\%) of 19 cases using uNGAL concentration versus 11 (58\%) of 19 cases using KIM-1 concentration).

The maximum biomarker levels in urine samples preceding AKI (T0) were then used to evaluate the diagnostic performances of both biomarkers for AKI prediction. The first urine samples of 49 patients who did not develop AKI served as controls. The clinical characteristics and outcomes of these 49 control patients did not differ from those of the 19 patients with AKI (all $P$-values >0.05). Maximum uNGAL and KIM-1 levels were observed at medians of 22 hours (IQR, 12 to 24) and 9 hours (IQR, 5 to 15), respectively, before reaching RIFLE-Risk level or higher for the first time. A contingency table analysis using a cutoff value $>126 \mathrm{ng} / \mathrm{ml}$ for UNGAL showed that the sensitivity of uNGAL was $84 \%$, its specificity was $86 \%$, its positive predictive value was $70 \%$ and its negative predictive value was $93 \%$ (Figure 5). At a cutoff value of $0.19 \mathrm{ng} / \mathrm{ml}$, the sensitivity of KIM-1 was $58 \%$, its specificity was $78 \%$, its positive predictive value was $50 \%$ and its negative predictive value was $83 \%$.

\section{Persistent acute kidney injury}

Of the 24 patients who had AKI upon admission, 13 had persistent AKI in the time frame between 48 and 72 hours, whereas the RIFLE score improved in 11. Biomarker levels did not differ significantly between groups.

\section{Discussion}

The aim of this study was to characterize uNGAL and KIM-1 patterns throughout the first days of ICU admission in critically ill children requiring mechanical ventilation and to assess their properties for identifying children who develop AKI. We show that levels of both biomarkers increased following admission and were significantly higher with worsening AKI severity. Most important, we found that UNGAL levels in the first 6 hours following admission can serve as a marker for identifying children meeting AKI criteria within 48 hours of ICU admission. Besides, when using the optimal cutoff uNGAL value (126 ng/ml), 16 of 19 patients in whom AKI was detected 24 hours later would have been diagnosed correctly. In contrast, KIM-1 was not found to be reliable in identifying children at risk for AKI. Thus, in a heterogeneous group of critically ill children, uNGAL may allow for an early diagnosis of AKI, even before a rise in $\mathrm{SCr}$ becomes apparent.

Of the 35 patients diagnosed with AKI within 48 hours following admission, a remarkable proportion of almost $70 \%$ already had AKI upon admission, including the most severe cases. These figures are in line with a large retrospective cohort study in which investigators evaluated 2,106 admissions to the PICU in whom AKI occurred predominantly on the first PICU day [2]. 


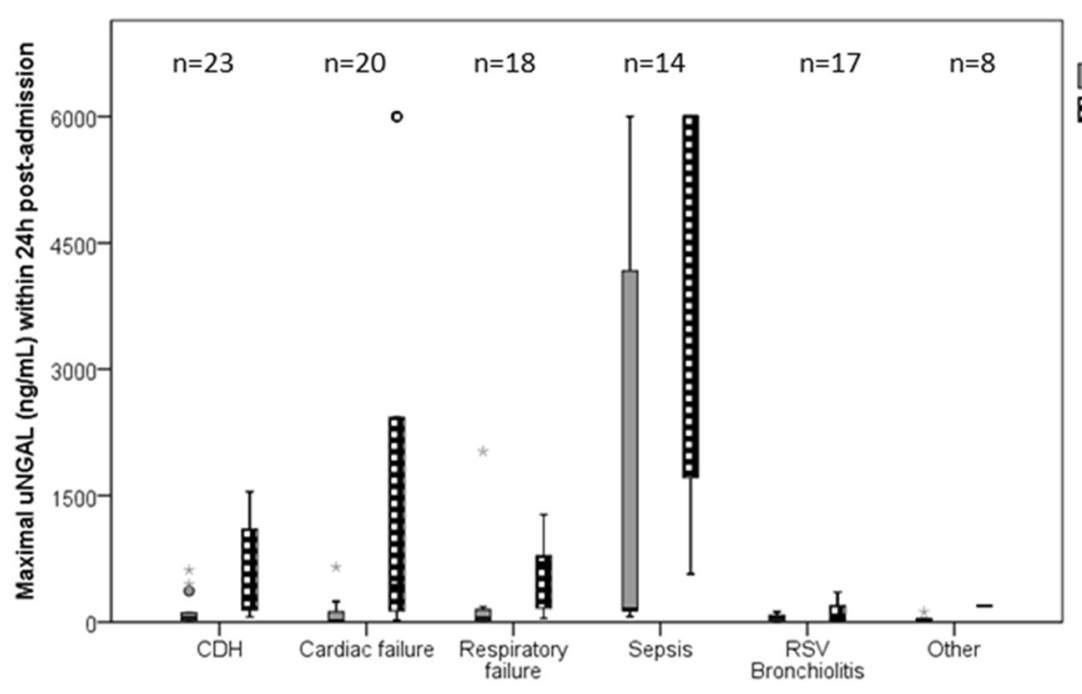

\section{$\square$ No AKI \\ 田AKI}

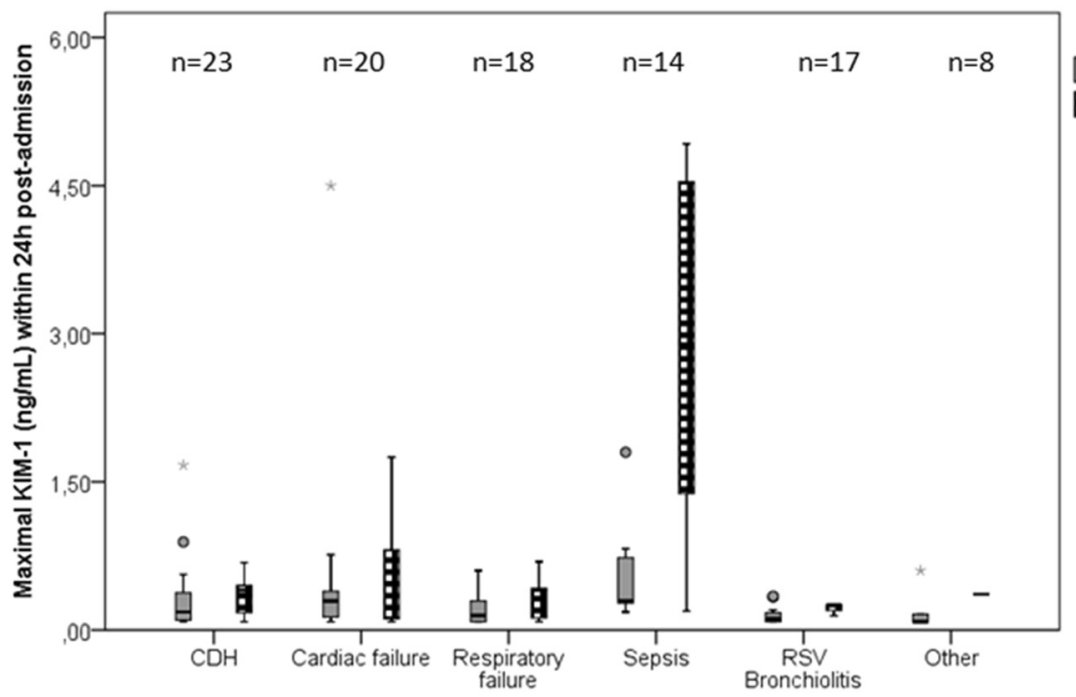

$\square$ No AKI

田AKI

Admission diagnosis

Figure 2 Maximal urinary neutrophil gelatinase-associated lipocalin and kidney injury molecule-1 levels within 24 hours post-admission, stratified by diagnosis upon admission (total number of patients $=100$ ). Data represent the mean $( \pm 1$ standard error of the mean). The black-and-white boxes represent patients with acute kidney injury (AKI), and the gray boxes represent non-AKI patients. Intergroup differences were assessed using Kruskal-Wallis tests. CDH, Congenital diaphragmatic hernia; KIM-1, Kidney injury molecule-1; RSV, Respiratory syncytial virus; UNGAL, Urinary neutrophil gelatinase-associated lipocalin.

Table 3 Occurrence of acute kidney injury within 48 hours following intubation ${ }^{a}$

\begin{tabular}{|c|c|c|c|c|c|c|c|}
\hline Biomarker & Number of patients (\%) & Time frame & AUC $(95 \% \mathrm{Cl})$ & $P$-value & Cutoff (ng/ml) & Sensitivity (\%) & Specificity (\%) \\
\hline \multirow[t]{4}{*}{ UNGAL } & $59(59 \%)$ & T0, 0 to $6 \mathrm{hr}$ & 0.815 (0.685 to 0.945$)$ & $<0.001$ & 126 & 76 & 84 \\
\hline & 85 (85\%) & $\mathrm{T} 1,6$ to $12 \mathrm{hr}$ & 0.780 (0.678 to 0.882$)$ & $<0.001$ & 88 & 70 & 74 \\
\hline & 95 (95\%) & $\mathrm{T} 2,12$ to $24 \mathrm{hr}$ & 0.711 (0.599 to 0.824$)$ & 0.001 & 32 & 72 & 62 \\
\hline & $100(100 \%)$ & 24-hr peak level & 0.811 (0.719 to 0.902$)$ & $<0.001$ & 1,338 & 80 & 77 \\
\hline \multirow[t]{4}{*}{ KIM-1 } & $58(57.4 \%)$ & T0, 0 to $6 \mathrm{hr}$ & $0.618(0.469$ to 0.768$)$ & 0.135 & 0.15 & 52 & 60 \\
\hline & $85(85 \%)$ & $\mathrm{T} 1,6$ to $12 \mathrm{hr}$ & 0.553 (0.469 to 0.729$)$ & 0.135 & 0.13 & 55 & 60 \\
\hline & 93 (931\%) & $\mathrm{T} 2,12$ to $24 \mathrm{hr}$ & 0.737 (0.628 to 0.847$)$ & $<0.001$ & 0.19 & 72 & 67 \\
\hline & $100(100 \%)$ & 24-hr peak level & 0.695 (0.584 to 0.807$)$ & 0.001 & 0.24 & 71 & 62 \\
\hline
\end{tabular}

${ }^{a} \mathrm{AUC}$, Area under the receiver operating characteristic curve; Cl, Confidence interval; KIM-1, Kidney injury molecule-1; uNGAL, Urinary neutrophil gelatinase-associated lipocalin. The optimal cutoff was based on the Youden index. 

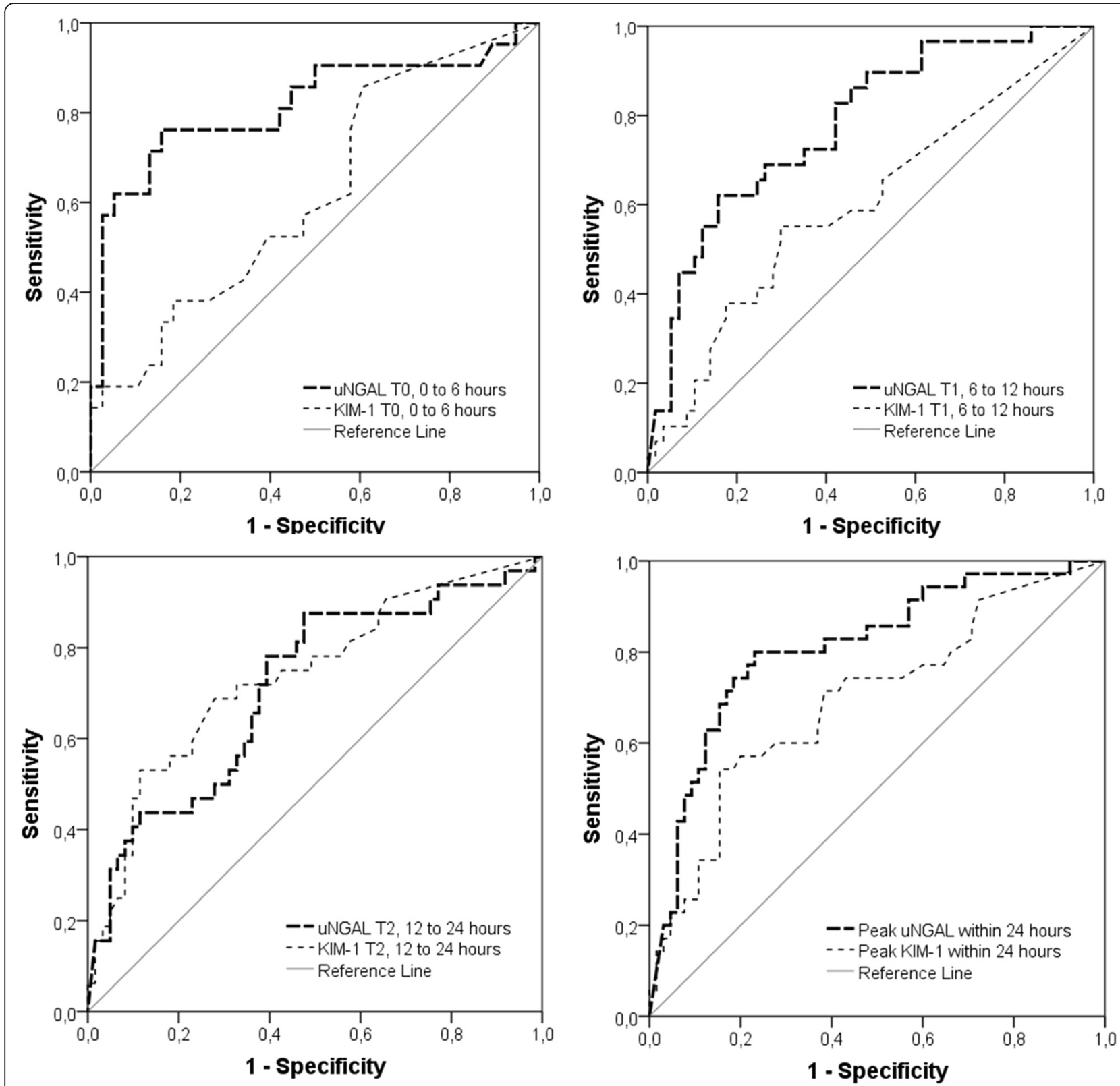

Figure 3 Receiver operating characteristic curves of urinary neutrophil gelatinase-associated lipocalin and kidney injury molecule-1 levels at time frames T0, T1 and T2 and for the 24-hour peak levels. The dashed black lines represent the receiver operating characteristic (ROC) curves of urinary neutrophil gelatinase-associated lipocalin (UNGAL), and the dotted lines represent the ROC curves of kidney injury molecule-1 (KIM-1). The gray lines represent the reference value.

Overall, we found notably higher UNGAL and KIM-1 biomarker levels than reported previously $[27,28]$. Zappitelli and colleagues reported a median peak UNGAL level of $55 \mathrm{ng} / \mathrm{ml}$ (IQR, 105) for patients with RIFLE-F, whereas we found a median value of $1,495 \mathrm{ng} / \mathrm{ml}$ (IQR, 387 to 6,000$)$ [28]. This is even more surprising in light of the fact that $23 \%$ of patients in the Zappitelli study had sepsis, compared with only $14 \%$ in our study. Our present study as well as other studies have shown that patients with sepsis have the highest levels of uNGAL and KIM-1, irrespective of AKI development, which is at least in part due to systemic inflammation $[25,31,35,36]$. Another explanation may lie in the lower severity of illness in the Zappitelli cohort, as reflected by a median PRISM II score of 19 (IQR, 12) [28] for the renal failure group compared with 48.9 (IQR, 25.5 to 77.1) in our patients with AKI. Furthermore, as uNGAL and KIM-1 levels in premature infants and young children generally are higher than healthy 

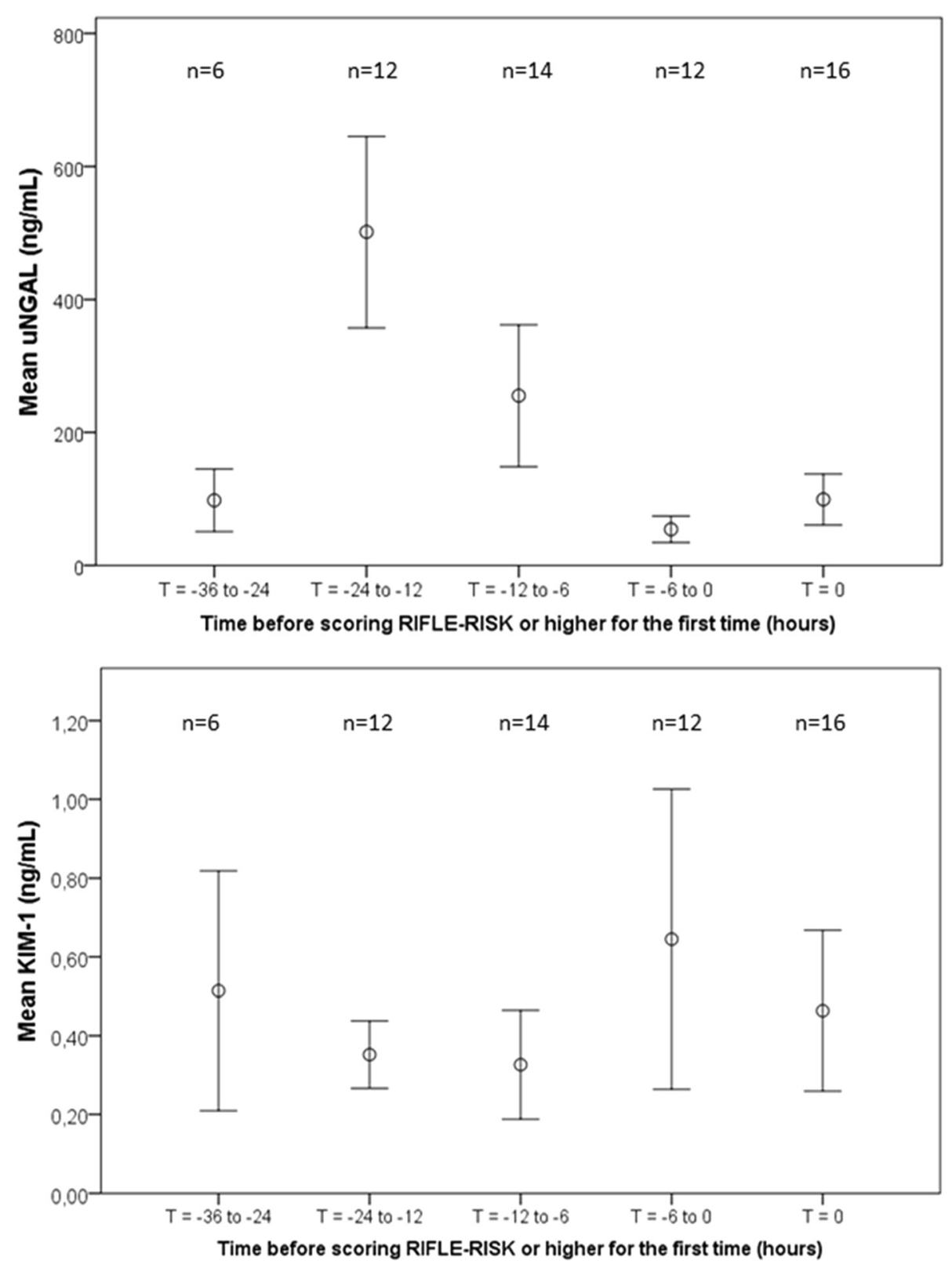

Figure 4 Urinary neutrophil gelatinase-associated lipocalin and kidney injury molecule-1 levels prior to the onset of acute kidney injury, defined as attaining RIFLE-Risk level or higher $(n=19)$. Data represent the mean $( \pm 1$ standard error of the mean). Acute kidney injury (AKI) was defined as a rise in serum creatinine of $150 \%$ or greater compared with age-specific reference values, which equals RIFLE-Risk level or higher. KIM-1, Kidney injury molecule-1; RIFLE, Risk, injury, failure, loss, end-stage renal disease; UNGAL, Urinary neutrophil gelatinase-associated lipocalin.

infants and young children, the younger age of our subjects might form another explanation [29,37,38]. Last, Zappitelli and colleagues used other biomarker kits [28].

We have shown that levels of both biomarkers increased following admission, with uNGAL levels peaking between 6 and 12 hours and KIM-1 levels peaking somewhat later, between 12 and 24 hours. These patterns resemble those reported in a well-conducted study of 543 adult ICU patients in which UNGAL levels in patients with AKI increased starting from the time of admission $(P<0.0001)$ and KIM-1 levels first differentiated between non-AKI and AKI patients 24 hours post-admission $(P=0.008)$ [39]. To the best of our knowledge, there are no pediatric studies available on the patterns of biomarkers following ICU admission using hourly time intervals. One study of 13 asphyxiated newborns reported uNGAL and KIM-1 levels on days 1 and 3 of life [27]. Notably, uNGAL levels in that study were increased but 

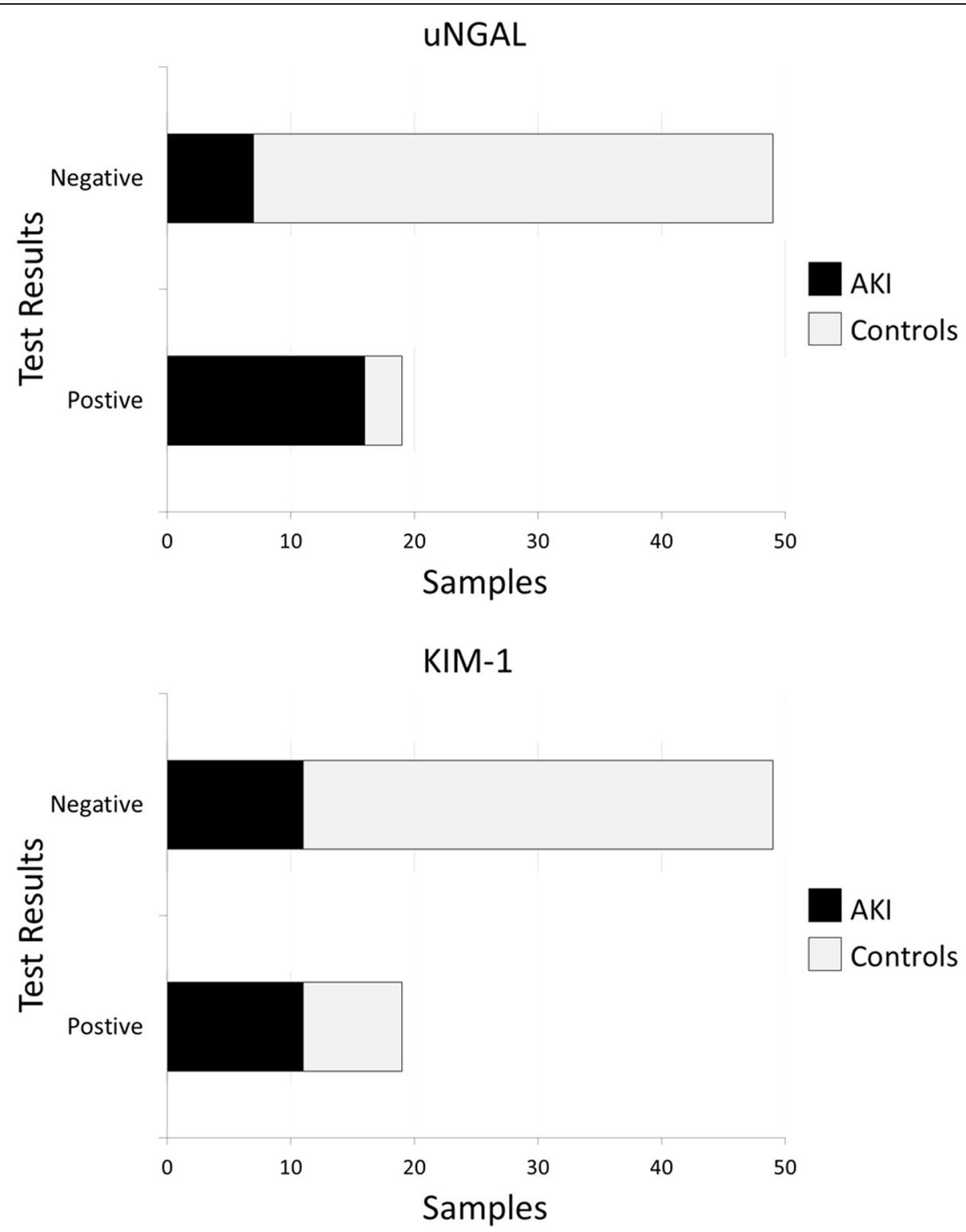

Figure 5 Results of contingency analysis. Bar graphs show the results of a contingency table analysis for urinary neutrophil gelatinase-associated lipocalin (UNGAL; cutoff value $=126 \mathrm{ng} / \mathrm{ml}$ ) and kidney injury molecule-1 (KIM-1; cutoff value of $0.19 \mathrm{ng} / \mathrm{ml})$. A total of 49 control samples were included (non-AKI critically ill), as well as 19 from critically ill children who developed AKI within 72 hours post-admission. AKI, Acute kidney injury.

remained stable, whereas KIM-1 levels were higher only on the first day of life and substantially decreased thereafter [27].

In our present study, uNGAL measured within 0 to 6 hours following admission had a reasonable ability (ROC-AUC $=0.815)$ to identify children meeting AKI criteria within 48 hours [25]. The AUC for uNGAL was in perfect line with previous reports in adults (AUCs 0.66 to 0.88 , depending on the severity of AKI). The optimal uNGAL cutoff value found $(126 \mathrm{ng} / \mathrm{ml}$; sensitivity of $75 \%$, specificity of $84 \%$ ) was slightly lower than reported for adults $(247 \mathrm{ng} / \mathrm{ml}$; sensitivity of $89 \%$ and specificity of $70 \%$ for prediction of renal failure) [40]. The discriminative ability of KIM-1, in contrast, is only limited, because all AUC values were $\leq 0.73$, which is consistent with previous reports [27,39]. All in all, the most robust NGAL results in critically ill children come from Mishra and colleagues for children who underwent $\mathrm{CPB}$. In their study, AKI timing and etiology post-CPB was well defined $[23,25]$.

Concerning the time relationship between the biomarker levels and AKI development, uNGAL levels in 
the present study peaked at 12 to 24 hours before reaching RIFLE-Risk level for the first time, whereas KIM-1 levels preceding AKI remained steady. A similar pattern for uNGAL levels was reported in a study of adults, but KIM-1 levels in that study did not rise until the time AKI was diagnosed [39]. Zappitelli and colleagues evaluated UNGAL levels relative to the day of pediatric RIFLE AKI attainment in 21 PICU patients [28]. Although they presented NGAL levels relative to urinary creatinine concentrations, it was clear that median NGAL levels peaked at 1 day before AKI onset [28]. Blood was sampled daily, however, instead of at hourly intervals.

The false-positive results of uNGAL (14\%) and KIM-1 (22\%) in the present study may be due to the limited specificity of both biomarkers, but one can also speculate that subclinical AKI occurred, a condition in which there is tubular damage without a rise in $\mathrm{SCr}$ as a sign of glomerular filtration alteration [10]. Still, uNGAL was able to predict AKI development correctly in 16 of 19 children, which further demonstrates its potential as an early marker of tubular damage. Identifying children in an early stage of AKI (for example, already at presentation in the emergency room or during clinical deterioration at the general ward) may help develop early interventions to limit the development of AKI. In this light, several studies have been published on potential protective properties of drugs against the development of AKI, including atrial natriuretic factor, such as in the cases of cisplatin treatment [41] and cardiac surgery [42], and administration of bovine-derived alkaline phosphatase in critically ill patients with sepsis-associated AKI [43]. Even though the rationale behind the renoprotective effects remains to be fully elucidated, these studies illustrate that new options in the prevention or limitation of the severity of AKI are currently being investigated.

Several limitations of this study should be addressed. First, this study has a single-center design, which may limit the generalization of the data to other institutions. Still, because we did not focus on diagnostic subclasses, our cohort can be considered a representative sample of the general PICU population younger than 1 year of age requiring mechanical ventilation. Second, the overall sample size was too small for multiple subgroup analyses. Besides, because we exclusively used SCr without urinary criteria for grading AKI severity, we may have underestimated the incidence and grade of AKI [44]. Furthermore, we were not able to collect all urine samples planned, especially not during the first hours of admission, when an indwelling urinary catheter yet had to be placed, when the urine portion was needed for clinical purposes (for example screening for metabolic diseases) or when a patient was anuric. Still, $86 \%$ of all planned samples were collected. Last, uNGAL and KIM-1 levels preceding AKI could be analyzed in only a small sample because most AKI patients already met RIFLE-Risk criteria or higher upon admission.

\section{Conclusions}

This study shows that both UNGAL and KIM-1 levels in critically ill infants with AKI increase following ICU admission and peak 6 to 12 hours and 12 to 24 hours thereafter, respectively. Notably, of the children who met AKI criteria within 48 hours following admission, almost $70 \%$ already had AKI upon admission to the ICU. Still, UNGAL reliably discriminated between infants who met AKI criteria within 48 hours following admission and those who did not. In addition, UNGAL was able to predict AKI development correctly in $84 \%$ of children before any rise in SCr became apparent. These findings support the emerging role of uNGAL in identifying AKI at an early stage, which may in the future help us to establish timely renoprotective interventions to reduce $\mathrm{AKI}$ in the most vulnerable patients in hospital.

\section{Key messages}

- Approximately 70\% of the children who develop AKI within 48 hours of admission already have AKI when entering the ICU.

- In children with AKI, there was a temporal pattern of increase in UNGAL and KIM-1 levels as they peaked between 6 to 12 hours and 12 to 24 hours, respectively, following admission.

- UNGAL concentrations at admission seems to be a reliable marker for identifying children who will develop AKI within 48 hours following admission.

\section{Abbreviations}

AKl: Acute kidney injury; AUC: Area under the receiver operating characteristic curve; $\mathrm{CDH}$ : Congenital diaphragmatic hernia; Cl: Confidence interval;

CKD: Chronic kidney disease; CPB: Cardiopulmonary bypass; CV: Coefficient of variation; ICU: Intensive care unit; IQR: Interquartile range; KIM-1: Kidney injury molecule-1; LoQ: Limit of quantification; PICU: Pediatric intensive care unit; PIM2: Pediatric Index of Mortality 2; PRISM II: Pediatric Risk of Mortality II; RIFLE: Risk, injury, failure, loss, end-stage renal disease; ROC: Receiver operating characteristic; RSV: Respiratory syncytial virus; SCr: Serum creatinine; UNGAL: Urinary neutrophil gelatinase-associated lipocalin.

\section{Competing interests}

The authors declare that they have no competing interests.

\section{Authors' contributions}

AJMZ carried out the study and wrote the manuscript. JVR and KC performed statistical analysis and interpretation of data. YBdR and EABB reviewed the manuscript and participated in biomarker assessment and data collection. SNdW, DT and KC contributed to study design and writing of the manuscript. All authors read and approved the final manuscript.

\section{Acknowledgements}

We thank Ko Hagoort for editorial assistance. We are also grateful to the research team, and specifically to Joke Dunk (research nurse), Miriam Mooij (doctoral student), Marie-Chantal Struijs (doctoral student), Nienke Vet 
(doctoral student) and Barry Koelewijn (for analytical assistance), for their contributions to this study. This study was supported by a grant from the Sophia Foundation for Scientific Research (633). The NGAL kits used in this study were a generous gift from Abbott (Abbott Diagnostics Division, Abbott Laboratories, Abbott Park, IL, USA).

\section{Author details}

'Intensive Care and Department of Pediatric Surgery, Wytemaweg 80, 3015 CN Rotterdam, the Netherlands. ${ }^{2}$ Department of Pediatric Nephrology, Erasmus Medical Center-Sophia Children's Hospital, Wytemaweg 80, 3015 CN Rotterdam, the Netherlands. ${ }^{3}$ Department of Biostatistics, Erasmus Medical Center, Wytemaweg 80, 3015 CN Rotterdam, the Netherlands. ${ }^{4}$ Department of Clinical Chemistry, Erasmus Medical Center, Wytemaweg 80, 3015 CN Rotterdam, the Netherlands. ${ }^{5}$ Department of Internal Medicine, Erasmus Medical Center, Wytemaweg 80, 3015 CN Rotterdam, the Netherlands.

Received: 30 December 2014 Accepted: 2 April 2015 Published online: 21 April 2015

\section{References}

1. Zwiers AJ, de Wildt SN, Hop WC, Dorresteijn EM, Gischler SJ, Tibboel D, et al. Acute kidney injury is a frequent complication in critically ill neonates receiving extracorporeal membrane oxygenation: a 14-year cohort study. Crit Care. 2013;17:R151

2. Alkandari $\mathrm{O}$, Eddington KA, Hyder A, Gauvin F, Ducruet T, Gottesman R, et al. Acute kidney injury is an independent risk factor for pediatric intensive care unit mortality, longer length of stay and prolonged mechanical ventilation in critically ill children: a two-center retrospective cohort study. Crit Care. 2011;15:R146

3. Bailey D, Phan V, Litalien C, Ducruet T, Mérouani A, Lacroix J, et al. Risk factors of acute renal failure in critically ill children: A prospective descriptive epidemiological study. Pediatr Crit Care Med. 2007:8:29-35.

4. Akcan-Arikan A, Zappitelli M, Loftis LL, Washburn KK, Jefferson LS, Goldstein SL. Modified RIFLE criteria in critically ill children with acute kidney injury. Kidney Int. 2007;71:1028-35.

5. Schneider J, Khemani R, Grushkin C, Bart R. Serum creatinine as stratified in the RIFLE score for acute kidney injury is associated with mortality and length of stay for children in the pediatric intensive care unit. Crit Care Med. 2010;38:933-9.

6. Plötz FB, Bouma AB, van Wijk JA, Kneyber MC, Bökenkamp A. Pediatric acute kidney injury in the ICU: an independent evaluation of pRIFLE criteria. Intensive Care Med. 2008;34:1713-7

7. Koralkar R, Ambalavanan N, Levitan EB, McGwin G, Goldstein S, Askenazi D. Acute kidney injury reduces survival in very low birth weight infants. Pediatr Res. 2011;69:354-8.

8. Bellomo R, Ronco C, Kellum JA, Mehta RL, Palevsky P. the ADQI workgroup. Acute renal failure - definition, outcome measures, animal models, fluid therapy and information technology needs: the Second International Consensus Conference of the Acute Dialysis Quality Initiative (ADQI) Group. Crit Care. 2004;8:R204-12.

9. Andreoli SP. Acute kidney injury in children. Pediatr Nephrol. 2009;24:253-63

10. Ronco C, Kellum JA, Haase M. Subclinical AKI is still AKI. Crit Care. 2012;16:313.

11. Schwartz GJ, Furth SL. Glomerular filtration rate measurement and estimation in chronic kidney disease. Pediatr Nephrol. 2007;22:1839-48.

12. Arant Jr BS. Postnatal development of renal function during the first year of life. Pediatr Nephrol. 1987;1:308-13.

13. Vanmassenhove J, Vanholder R, Nagler E, Van Biesen W. Urinary and serum biomarkers for the diagnosis of acute kidney injury: an in-depth review of the literature. Nephrol Dial Transplant. 2013;28:254-73.

14. Kjeldsen $L$, Johnsen $A H$, Sengeløv $H$, Borregaard N. Isolation and primary structure of NGAL, a novel protein associated with human neutrophil gelatinase. J Biol Chem. 1993;268:10425-32.

15. Xu S, Venge P. Lipocalins as biochemical markers of disease. Biochim Biophys Acta. 2000;1482:298-307.

16. Cowland JB, Borregaard N. Molecular characterization and pattern of tissue expression of the gene for neutrophil gelatinase-associated lipocalin from humans. Genomics. 1997;45:17-23.
17. Kuwabara T, Mori K, Mukoyama M, Kasahara M, Yokoi H, Saito Y, et al. Urinary neutrophil gelatinase-associated lipocalin levels reflect damage to glomeruli, proximal tubules, and distal nephrons. Kidney Int. 2009;75:285-94

18. Devarajan P. Neutrophil gelatinase-associated lipocalin: a promising biomarker for human acute kidney injury. Biomark Med. 2010;4:265-80.

19. Schmidt-Ott KM, Mori K, Li JY, Kalandadze A, Cohen DJ, Devarajan P, et al. Dual action of neutrophil gelatinase-associated lipocalin. J Am Soc Nephrol. 2007;18:407-13.

20. Mori K, Lee HT, Rapoport D, Drexler IR, Foster K, Yang J, et al. Endocytic delivery of lipocalin-siderophore-iron complex rescues the kidney from ischemia-reperfusion injury. J Clin Invest. 2005;115:610-21.

21. Ichimura T, Bonventre JV, Bailly V, Wei H, Hession CA, Cate RL, et al. Kidney injury molecule-1 (KIM-1), a putative epithelial cell adhesion molecule containing a novel immunoglobulin domain, is up-regulated in renal cells after injury. J Biol Chem. 1998;273:4135-42.

22. Bailly V, Zhang Z, Meier W, Cate R, Sanicola M, Bonventre JV. Shedding of kidney injury molecule-1, a putative adhesion protein involved in renal regeneration. J Biol Chem. 2002:277:39739-48.

23. Mishra J, Dent C, Tarabishi R, Mitsnefes MM, Ma Q, Kelly C, et al. Neutrophi gelatinase-associated lipocalin (NGAL) as a biomarker for acute renal injury after cardiac surgery. Lancet. 2005;365:1231-8.

24. Haase-Fielitz A, Haase M, Devarajan P. Neutrophil gelatinase-associated lipocalin as a biomarker of acute kidney injury: a critical evaluation of current status. Ann Clin Biochem. 2014;51:335-51.

25. Haase M, Bellomo R, Devarajan P, Schlattmann P, Haase-Fielitz A. NGAL Meta-analysis Investigator Group. Accuracy of neutrophil gelatinaseassociated lipocalin (NGAL) in diagnosis and prognosis in acute kidney injury: a systematic review and meta-analysis. Am J Kidney Dis. 2009:54:1012-24

26. Shao X, Tian L, Xu W, Zhang Z, Wang C, Qi C, et al. Diagnostic value of urinary kidney injury molecule 1 for acute kidney injury: a meta-analysis. PLoS One. 2014;9, e84131.

27. Sarafidis K, Tsepkentzi E, Agakidou E, Diamanti E, Taparkou A, Soubasi V, et al. Serum and urine acute kidney injury biomarkers in asphyxiated neonates. Pediatr Nephrol. 2012;27:1575-82.

28. Zappitelli M, Washburn KK, Arikan AA, Loftis L, Ma Q, Devarajan P, et al. Urine neutrophil gelatinase-associated lipocalin is an early marker of acute kidney injury in critically ill children: a prospective cohort study. Crit Care. 2007;11:R84

29. Wai K, Soler-García ÁA, Perazzo S, Mattison P, Ray PE. A pilot study of urinary fibroblast growth factor-2 and epithelial growth factor as potential biomarkers of acute kidney injury in critically ill children. Pediatr Nephrol. 2013;28:2189-98.

30. Hoffman SB, Massaro AN, Soler-García AA, Perazzo S, Ray PE. A novel urinary biomarker profile to identify acute kidney injury (AKI) in critically ill neonates: a pilot study. Pediatr Nephrol. 2013;28:2179-88.

31. Merrikhi A, Gheissari A, Mousazadeh $H$. Urine and serum neutrophil gelatinase-associated lipocalin cut-off point for the prediction of acute kidney injury. Adv Biomed Res. 2014;3:66.

32. Slater A, Shann F, Pearson G. Paediatric Index of Mortality (PIM) Study Group. PIM2: a revised version of the Paediatric Index of Mortality. Intensive Care Med. 2003;29:278-85.

33. Pollack MM, Patel KM, Ruttimann UE. PRISM III: an updated Pediatric Risk of Mortality score. Crit Care Med. 1996;24:743-52.

34. Boer DP, de Rijke YB, Hop WC, Cransberg K, Dorresteijn EM. Reference values for serum creatinine in children younger than 1 year of age. Pediatr Nephrol. 2010;25:2107-13.

35. Di Nardo M, Ficarella A, Ricci Z, Luciano R, Stoppa F, Picardo S, et al. Impact of severe sepsis on serum and urinary biomarkers of acute kidney injury in critically ill children: an observational study. Blood Purif. 2013;35:172-6.

36. Smertka M, Wroblewska J, Suchojad A, Majcherczyk M, Jadamus-Niebroj D, Owsianka-Podlesny T, et al. Serum and urinary NGAL in septic newborns. Biomed Res Int. 2014;2014:717318.

37. Zwiers AJ, de Wildt SN, de Rijke YB, Willemsen SP, Abdullahi NS, Tibboel D, et al. Reference intervals for renal injury biomarkers neutrophil gelatinaseassociated lipocalin and kidney injury molecule-1 in young infants. Clin Chem Lab Med. 2015 Feb 7, [Epub ahead of print]. doi:10.1515/cclm-2014-1020.

38. Askenazi DJ, Koralkar R, Levitan EB, Goldstein SL, Devarajan P, Khandrika S, et al. Baseline values of candidate urine acute kidney injury biomarkers vary by gestational age in premature infants. Pediatr Res. 2011;70:302-6. 
39. de Geus HR, Fortrie G, Betjes MG, van Schaik RH, Groeneveld AB. Time of injury affects urinary biomarker predictive values for acute kidney injury in critically ill, non-septic patients. BMC Nephrol. 2013;14:273.

40. de Geus HR, Bakker J, Lesaffre EM, le Noble JL. Neutrophil gelatinaseassociated lipocalin at ICU admission predicts for acute kidney injury in adult patients. Am J Respir Crit Care Med. 2011;183:907-14.

41. Nojiri T, Hosoda H, Kimura T, Miura K, Ishikane S, Tokudome T, et al. Atrial natriuretic peptide protects against cisplatin-induced acute kidney injury. Cancer Chemother Pharmacol. 2015;75:123-9.

42. Patel NN, Angelini GD. Pharmacological strategies for the prevention of acute kidney injury following cardiac surgery: an overview of systematic reviews. Curr Pharm Des. 2014;20:5484-8.

43. Peters E, Masereeuw R, Pickkers P. The potential of alkaline phosphatase as a treatment for sepsis-associated acute kidney injury. Nephron Clin Pract. 2014;127:144-8.

44. Wlodzimirow KA, Abu-Hanna A, Slabbekoorn M, Chamuleau RA, Schultz MJ, Bouman CS. A comparison of RIFLE with and without urine output criteria for acute kidney injury in critically ill patients. Crit Care. 2012;16:R200.

\section{Submit your next manuscript to BioMed Central and take full advantage of:}

- Convenient online submission

- Thorough peer review

- No space constraints or color figure charges

- Immediate publication on acceptance

- Inclusion in PubMed, CAS, Scopus and Google Scholar

- Research which is freely available for redistribution 